\title{
Sensory analysis: methodological aspects relevant to the study of cheese
}

\author{
S Issanchou, P Schlich, I Lesschaeve \\ Laboratoire de Recherches sur les Arômes, INRA, BV 1540, 21034 Dijon Cedex, France
}

\begin{abstract}
Summary - The main requirements for reliable sensory descriptive data are presented in this text. The importance of panellist selection is emphasised and some guidelines and examples are given. The steps identified for obtaining a sensory profile are detailed. Some vocabulary lists developed for cheese evaluation are presented. Advice is given on the conditions required for the collection of sensory descriptive data and attention is focussed on the presentation order. Statistical tools recently proposed to evaluate the performance of the sensory panellists are referred to. Two multivariate methods of statistical analysis, Generalised Procrustres Analysis (GPA) and STATIS, particularly suited to the analysis of the sensory descriptive data, are discussed. Finally, expertise required by the person responsible for sensory evaluation is detailed.
\end{abstract}

sensory profiling / panel selection / panel training / assessor performance / statistical method / cheese

Résumé - Analyse sensorielle : aspects méthodologiques importants pour l'étude du fromage. Bien que certaines caractéristiques sensorielles puissent être appréhendées par des mesures instrumentales, la méthode la plus directe, à savoir celle utilisant l'homme comme instrument de mesure, reste la plus exacte. La mesure instrumentale ne peut s'y substituer que si les données ainsi obtenues sont bien corrélées aux données sensorielles. Dans ce texte, les différents aspects de la mise en place et de la réalisation des essais sensoriels visant à obtenir une description des produits sont exposés. L'attention est attirée sur les procédures et précautions nécessaires pour l'obtention de mesures sensorielles fiables, condition indispensable à la reconnaissance de l'analyse sensorielle comme méthode primordiale de caractérisation de produits alimentaires. L'accent est mis, en particulier, sur le groupe de sujets, cœur de la mesure sensorielle. Certaines déficiences, telles que les hypos-

Oral communication at the IDF Symposium 'Ripening and Quality of Cheeses', Besançon, France, February 26-28, 1996. 
mies spécifiques, ne pouvant être corrigées par l'entraînement, il est indispensable de débuter par une phase de sélection. La nécessité de développer des tests de sélection spécifiques au produit étudié et à la tâche que devront effectuer les sujets est soulignée et, à titre d'exemple, les objectifs et le contenu de certains des tests de sélection utilisés pour la sélection d'un groupe de sujets devant travailler sur la description de camemberts sont présentés. La phase d'établissement d'une liste de descripteurs, phase la plus longue et la plus délicate du processus de mise en place de la caractérisation sensorielle, est décrite, et l'importance d'une définition précise de la préparation et de la présentation des échantillons de fromages et des protocoles d'évaluation est soulignée. Des listes de descripteurs proposées dans la littérature pour la caractérisation des fromages sont indiquées, ainsi que les précautions indispensables à prendre pour l'utilisation de telles listes. Lors de l'entraînement et à l'issue de chaque série de mesures, les performances des sujets doivent être suivies; les critères à examiner sont, pour chaque sujet et chaque descripteur, l'utilisation de l'échelle, le pouvoir discriminant, la répétabilité et l'accord entre les sujets. Des outils statistiques de suivi de ces critères de performances des sujets récemment développés sont présentés. Deux méthodes multidimensionnelles, l'analyse procrustéenne généralisée et STATIS, permettant la prise en compte des différences interindividuelles sont comparées. Pour conclure, les auteurs soulignent les compétences requises pour le responsable de l'analyse sensorielle chargé de mettre en place les essais et d'animer le groupe de sujets.

\section{profil sensoriel / sélection / entraînement / performance du sujet / méthode statistique / fromage}

\section{INTRODUCTION}

Sensory characteristics are an important determinant in the choice of the food products by the consumer. Therefore, the measurement of sensory characteristics is an important point for the producer. Sensory analysis is the most direct and thus the most valid way of measuring the organoleptic characteristics (Piggott, 1995). Instrumental measurements could replace the sensory ones only if they have been validated by experiments showing strong correlations between both sets of data and if the predictive value of the instrumental measurements have been demonstrated. Sensory measurements are often described as 'subjective' measurements; this is true as the measuring instrument is a panel of subjects, but this does not mean that these subjects are not objective, as discussed by Sauvageot (1986). Subjects in a panel are requested to disregard their personal liking and to concentrate on the description of their perceptions. To perform such measurements, trained subjects are used, whereas consumers, ie, naive subjects, are used for hedonic measurements.
Sensory measurements can be carried out to answer questions such as "Is there a perceptible difference between two or more samples?" and "What are the sensory differences between the samples?". The present paper will be devoted to the profiling method which permits answers to the last type of question. Our aim was not to give a complete guide for sensory profiling. We have chosen to concentrate on points that we consider to be particularly important.

\section{THE PANEL}

The most important point in sensory measurements is the panel. Thus, care is required in setting up the panel. The first step is to recruit the subjects within or outside the company. In both cases, the first criteria to be taken into account are motivation and availability. The greatest problem with an internal panel is that participation in sensory tests is a supplementary task. Moreover, the number of candidates is generally too low to perform a selection based on the candidates' abilities. However, this is essential. Indeed, training cannot correct some deficiencies 
such as specific anosmia, which is due to lack of some olfactory receptors. Such anosmia can occur for potent odorants in cheese flavour. For example, anosmia was described by Amoore (1977) for diacetyl and by Boelens et al (1983) and Brennand et al (1989) for 4-ethyloctanoic acid, a key compound for goat cheese flavour. Moreover, some links between initial abilities during the selection stage and the capacity to discriminate Camembert samples for their flavour have been observed (Lesschaeve and Issanchou, 1995).

Many authors agree that the selection stage needs to be product-specific and must be adapted to the sensory task required. The following abilities need to be investigated through the selection tests: normal acuity for the different senses which will be involved in the future task, ability to memorise and recognise flavours, ability to express oneself about sensory perceptions, ability to deal analytically with complex foods. The ability to discriminate samples differing in their intensity on a characteristic can also be investigated, but can be improved by training. Besides these abilities, other criteria such as health status, willingness to work cooperatively with others in a group setting, ability to understand the task and to follow the instructions should be taken into account. These points are generally examined by interviewing the candidates before the final selection. Sensory profiling of sensory characteristics demands the ability to quickly focus on the task. The test Bourdon TIB (Swets and Zeitlinger BV, Calisse, The Netherlands) has been used to estimate the concentration ability of subjects and it appeared that panellists who have lower scores at this test tend to be more unreliable than the others (Lesschaeve and Issanchou, 1995). Such a result needs to be confirmed by other experiments, and other tests could be investigated as the Bourdon test involves not only concentration ability but also visual ability.

In order to have a sufficient number of subjects with a score higher than a predetermined value for each test, it is necessary to screen a large number of candidates (at least one hundred). As far as possible, the stimuli used for the selection tests must be chosen with knowledge of the product to be studied. For example, stimuli used to evaluate the taste acuity of candidates for a Camembert cheese panel were lactose, lactic acid and $\mathrm{L}$-leucine respectively for sweetness, acidity and bitterness; and stimuli used to evaluate the olfactory sensitivity and culture were chosen because their odour quality was noted in Camembert cheeses in previous studies (Issanchou et al, 1995).

An important issue is the number of assessors required to carry out profiling. In the literature, the descriptive panel size varies from eight, the recommended minimum number according to Lyon et al (1992), to 24 (eg, Muir and Hunter, 1991-1992). The size of the panel can be reduced if highly trained subjects are used. However, even with trained subjects, it is clear that if the panel is too small the results will be too dependent on individual sensitivities. Moreover, from a statistical point of view the smaller the size of the panel, the larger the chance of not detecting a small difference. Thus, eight highly trained subjects is a minimum.

\section{THE PROFILING METHOD}

It is necessary to distinguish different steps when a profile has to be carried out. The first step concerns the collection of the descriptors and the choice of the response scales; the second step concerns the measurements. Different methods concerning these two steps have been proposed and reviewed by several authors (eg, Sauvageot, 1990; Meilgaard et al, 1991). The procedures which will be presented here are those in which each subject evaluates the samples independently and where the results are analysed by statistical techniques.

In the conventional profile, the list of descriptors is identical for all the subjects, whereas with the free-choice procedure proposed by Williams and Langron (1984) each subject used his/her own list of descriptors. The advantage of the free-choice procedure is to considerably reduce the duration of the training, as it is not neces- 
sary to train the subjects to use the descriptors in the same way. This method has been often used with unscreened and untrained subjects. However, in our opinion, to obtain as complete a description as possible subjects need to be selected on their ability to describe their perceptions. They also need a basic training and need to be well-familiarised with the range of products to be studied. Sophisticated multivariate methods are required to analyse the data. The largest disadvantage is that the multidimensional maps which are obtained by such methods are often very difficult to interpret because a large number of descriptors are used and the same word can be used very differently. For example, Jack et al (1993) observed that 'yellow' indicates a strong yellow colour for some subjects and a creamy colour for others. If such difficulties are easily solved for appearance and colour description, this is not the case for aroma description. Thus, the free-choice profiling method is recommended when a limited study of a group of products is required, or as a preliminary step to develop a list of descriptors as used by Parolari et al (1994).

For conventional procedure, all assessors contribute to the generation of descriptive terms. An ISO standard describes a procedure for establishing a list of attributes (ISO, 1995). In our opinion, this standard does not sufficiently emphasise the importance of the discussion at the end of each session during the generation phase which seeks to eliminate ambiguities as soon as possible. Moreover, some rankings or comparative ratings followed by a comparison of the results of all panellists must be performed at an early stage of vocabulary development in order to detect disagreements between the subjects. Finally, as mentioned previously by Sauvageot (1991), the suggested number of 15 attributes seems low for a complete profile (appearance, odour, flavour and texture).

To shorten this step, a list of descriptors established from previous studies on the same type of products can be used to start the work. To be useful, each descriptor of such a list must be accompanied by a definition and a reference.
But the experimenter must be aware that the way of using a descriptor and a response scale varies with the sample space under study. Thus training sessions must be organised to establish accurate definitions of terms, to determine procedure to evaluate each property and to define scale anchor points. For example, Vangtal and Hammond (1986) working on Swiss-type cheeses have proposed a list of eight descriptors established in a previous study, but this list was expanded to 16 descriptors during the ten one-hour training sessions as the cheeses used in the experiment contained flavour notes not encountered in the previous one. As previously established for wine (Noble et al, 1984) and beer (Meilgaard et al, 1979), a wheel of sensory attributes has been proposed for cheese (Pagliarini et al, 1991). However, the applicability of this list is limited because it has been established from published studies on a limited number of cheese types and because no definitions or standards are provided. The 30-flavour descriptor list developed by Heisserer and Chambers (1993) from the evaluation of a larger range of matured natural cheeses varying in milk source, country of origin and type of process is more relevant. Moreover, the interest of this work is that, for each descriptor, a definition and a reference is given. However, such a list may not be useful for describing sample differences of one particular cheese; some attributes will be useless, and other will be missed. Furthermore, some references are not cheese-specific, eg, caffeine and sucrose respectively for bitterness and sweetness; and some are not the most typical of references, eg, hexanoic acid for goaty flavour. Descriptive vocabularies have recently been published for 20 dairy products (CIDIL, 1995). They have been established by conducting sensory evaluation with product experts, but no references are provided and the number of flavour attributes is always limited.

For texture profiling, the most clearly documented work is The Guide for the Evaluation of Hard and Semi-Hard Cheeses (Lavanchy et al, 1994). In this guide, the shape and size of the cheeses samples are given, the evaluation pro- 
cedure is described and references are given for three points of each response scale. The evaluation procedure is particularly important for texture evaluation, but can also be important for flavour evaluation. For example, to evaluate a blue cheese flavour it is necessary to scrape the surface of the cheese to obtain a homogeneous sample (CIDIL, 1995).

\section{CONDITIONS FOR THE COLLECTION OF DATA}

For detailed information about the test room design, the reader can refer to Stone and Sidel (1985) or Meilgaard et al (1991). Samples must be coded, preferably with three-digit random numbers; tables are provided by Meilgaard et al (1991). When measuring flavour, masking colour differences through the use of coloured lights can prevent bias. However, cheeses differ often not only in colour but in appearance; this cannot be masked.

Temperature fluctuations between sessions may induce unwanted changes in texture as well as in flavour perceptions. Temperature must therefore be carefully controlled. Lavanchy et al (1994) used a temperature of $16^{\circ} \mathrm{C}$, which corresponds to that recommended for cheese consumption. Serving size must also be carefully regulated.

The number of products presented in one session will depend on the number of attributes to be evaluated and on the nature of the cheese (if the cheese has a strong flavour, fewer samples could be assessed). Moreover, some cheeses are quite adhesive; thus residues of the previous samples can modify the following evaluation. It is recommended that subjects be provided with a palate cleanser. For cheese evaluation, apple and water can be used (Piggott and Mowat, 1991); the apple must be placed in an airtight box to prevent the diffusion of its odour in the sensory room.

A rinsing procedure does not allow complete elimination of order and carry-over effects. Moreover, carry-over effects, and particularly first-order carry-over effect (ie, the effect of the previous sample), can also be due to contrast or convergence biases. A contrast error occurs when a sample with a low intensity for one property is followed by a sample with a high intensity for the same property; in this case, the intensity of the second sample and thus the difference between the two samples could be overestimated. On the contrary, a convergence effect occurs when a sample with a high intensity for one property is followed by a sample with a low intensity for the same property; in this case, the intensity of the second sample can be underestimated. In order to minimise such effects, William's Latin squares should be used. MacFie et al (1989) have established tables of presentation orders according such Latin squares for a session with four to 16 samples and a panel size of about 50 subjects. Muir and Hunter (1991-1992), in a study on Cheddar cheese, have tested order and carry-over effects and have shown an effect of the previous sample for two descriptors (fruity and sulphur) and a position effect for odour intensity (the first product evaluated being stronger than the following) and for the 'fruity', the 'rancid' and the 'cowy' aroma characteristics (the first product evaluated being less intense than the following).

The total number of samples to analyse is often larger than the number of samples which can be presented in one session. In such cases, an experimental design must be constructed in terms of sample allocation per session and per assessor, taking the constraints into account. For example the samples within a session are often identical for all assessors, which is not the best solution. However, what the experimental design should achieve must be clearly defined before its construction. In order to evaluate assessors' performance and especially agreement among them, samples must be assessed at least in duplicate. A complete design where all samples are evaluated the same number of times by all panellists is easier to analyse than an incomplete design. However, in some cases it could be useful to use a balanced incomplete design (Gacula and Singh, 1984). 


\section{PERFORMANCE ASSESSMENT OF DESCRIPTIVE PANELLISTS}

To demonstrate the reliability of the sensory data, it is necessary to monitor the assessors' performance during training and after each series of experimental measurements. A number of tools have been recently developed to monitor assessors performance and detect the differences between subjects (eg, Gatchalian et al, 1991; Naes and Solheim, 1991; PritchettMangan, 1992; Naes et al, 1994; Schlich, 1994). As described by Naes (1990), there are different ways for assessors to differ in the use of a response scale. Assessors can differ in their mean score: some assessors tend to give higher scores than others for all the products; this is called a level effect, and is taken into account by introducing an assessor effect in the model for the analysis of variance (ANOVA). Assessors can also differ in the span of their scores: some will tend to make larger differences between products than others; this is called a range effect. In some cases, the degree of similarity between pairs of products differs from one subject to another. Such interindividual differences can be due to a difference in sensitivity or in the interpretation of the descriptor. The training cannot solve the differences in sensitivity, but can reduce the disagreement due to the last source. Thus it is useful to examine for each subject and each descriptor the mean level and span. The training should be continued if the level or span is too low. The performance of each subject must also be examined by an individual ANOVA where the error will give an estimation of the repeatability of the subject and the variance ratio $(F)$ associated with the product effect an estimation of the discrimination power of the subject. Finally, the agreement among subjects must be estimated through the variance ratio $(F)$ associated with the interaction between the product and the assessor effect, and by calculating the contribution of each assessor to this interaction. The programme GRAPES, developed by Schlich (1994), computes and gives a graphic representation of such indices. Concerning the agreement among subjects, some authors suggest working on the product ranks instead of on the product scores. Kendall's coefficient of concordance can be calculated to estimate the degree of agreement among subjects and a Spearman coefficient can be calculated to estimate the agreement of each subject with the rest of the group. A more informative method has been proposed which allows a graphic representation of the differences (egg-shell plot; Naes et al, 1994). The advantage of these methods based on the ranks is that they do not require any replication. It is important to examine at the same time the discrimination power and the level of disagreement, as some assessors can be largely responsible for the interaction - not because they are 'poor' subjects, but because they are the only discriminant subjects. It must also be emphasised that a subject can differentiate products on one attribute, and deduce the scores for all the other descriptors from this attribute; this is called a halo effect. Thus, it is necessary to check the discrimination power at a multivariate level. To do this, it is possible to perform a stepwise discriminant analysis for each subject and to calculate the average squared canonical correlation for the selected variables (descriptors); if this coefficient is equal to zero, it means that the subject does not perceive any difference between the samples; if it is equal to 1 , it means that the subject is able to discriminate each sample from the others. The complexity of the sensory space can be estimated through the number of discriminant axes (Lesschaeve and Issanchou, 1995).

\section{MULTIVARIATE ANALYSIS OF PROFILING DATA}

To determine if the samples are significantly different for each descriptor, an ANOVA must be performed for each descriptor. For information about univariate analysis, the reader can refer to Gacula and Singh (1984). We have chosen to concentrate on multivariate methods which are very useful to summarise information in the data profile and to examine relations between attributes. Principal component anal- 
ysis is certainly the most frequently used method: the reader will find an application of this method to processed cheese profiling data reported by Ellekjaer et al (1996).

In this paper, we present two methods which are particularly suited to the analysis of sensory descriptive data. Different multivariate methods have been proposed to analyse profiling data while taking into account individual differences and especially the fact that, even after a thorough training, different assessors can use the same descriptor to measure different sensory concepts. The Generalised Procrustes Analysis (GPA) proposed by Gower (1975) is the most frequently used method, and more recently the usefulness of the STATIS method has been demonstrated. For the interested statistician, Schlich (1996) has provided a full technical explanation concerning this last method. GPA is an iterative procedure which defines a consensus among assessors from product differences. Improvements in GPA have been recently proposed; thus, Wakeling et al (1992) have defined a test of the significance of the consensus based on permutations of the product labels by assessors. The principle of the STATIS method (Lavit, 1988) is to take into account the distances between the products of the individual spaces to calculate a weighted mean table of the distances, called a compromise. The weight of each assessor in the compromise is proportional to his/her agreement with the panel. Unlike GPA, STATIS is a non-iterative method. STATIS offers some advantages over the GPA as it permits testing of the validity of the compromise without computing numerous permutations, and testing the agreement between two individual spaces (Schlich, 1996).

\section{CONCLUSION}

Considerable progress has been made in sensory evaluation methodology over the last three decades. The importance of controlling the test conditions has been noted, and sensory methods are supported by more advanced and effective statistical techniques.
In this paper, the importance of the panel has been emphasised. Investment of time and thus money is necessary to set up a sensory panel. To conclude, we would like to focus attention on the expertise required by the manager of the sensory panel. Through the description of sensory methods and some of its pitfalls, it is clear that the person in question requires some knowledge of different fields (sensory physiology, psychophysics, food science, managing of group dynamics and statistics). Such expertise and a trained panel are the price to be paid for obtaining reliable sensory data.

The authors hope that the methods and recommendations presented here may help those involved in the sensory field, and convince them that sensory analysis is an essential tool in the characterisation of cheese products.

\section{REFERENCES}

Amoore JE (1977) Specific anosmia and the concept of primary odors. Chem Senses Flavor 2, 267-281

Boelens H, Haring HG, de Rijke D (1983) Threshold values of and human preferences for 4-ethyl octanoic and 3-methyl butanoic acid. Perfum Flavor 8 (Feb/March), 71-74

Brennand CP, Ha JK, Lindsay RC (1989) Aroma properties and thresholds of some branched-chain and other minor volatile fatty acids occurring in milkfat and meat lipids. I Sens Stud 4, 105-120

CIDIL (1995) L'évaluation sensorielle appliquée aux produits laitiers. CIDIL, Paris

Ellekjaer MR, Ilseng MA, Naes T (1996) A case study of the use of experimental design and multivariate analysis in product improvement. Food Qual Pref 7, 29-36

Gacula MC, Singh J (1984) Statistical Methods in Food and Consumer Research. Academic Press, Orlando, FL

Gatchalian MM, De Leon SY, Yano T (1991) Control chart technique; a feasible approach to measurement of panelist performance in product profile development. J Sens Stud 6, 239-254

Gower JC (1975) Generalized Procrustes analysis. Psychometrika 40, 33-50 
Heisserer DM, Chambers IV EC (1993) Determination of the sensory flavor attributes of aged natural cheese. J Sens Stud 8, 121-132

ISO (1995) Analyse sensorielle. Méthodologie. Recherche et sélection de descripteurs pour l'élaboration d'un profil sensoriel, par approche multidimensionnelle. NF ISO 11035 AFNOR, Paris

Issanchou S, Lesschaeve I, Köster EP (1995) Screening individual ability to perform descriptive analysis of food products: basic statements and application to a Camembert cheese descriptive panel. J Sens Stud 10, 349-368

Jack FR, Piggott JR, Paterson A (1993) Discrimination of texture and appearance in Cheddar cheese using consumer free-choice profiling. J Sens Stud 8 , 167-176

Lavanchy P, Berodier F, Zannoni M, Noel Y, Adamo C, Squella J, Herrero L (1994) A Guide to the Sensory Evaluation of Texture of Hard and Semi-Hard Cheeses. INRA, Paris

Lavit C (1988) Analyse conjointe de tableaux quantitatifs. Masson, Paris

Lesschaeve I, Issanchou S (1995) Could selection tests detect the future performance of descriptive panelists ? In: 2nd Pangborn Sensory Sci Symp, Davis, CA, 30 July-3rd August

Lyon DH, Francombe MA, Hasdell TA, Lawson K (1992) Guidelines for Sensory Analysis in Food Product Development and Quality Control. Chapman and Hall, London

MacFie HJ, Bratchell N, Greenhoff K, Vallis LV (1989) Designs to balance the effect of order of presentation and first-order carry-over effects in Hall tests. J Sens Stud 4, 129-148

Meilgaard MC, Dalgliesh CE, Clapperton JF (1979) Beer flavor terminology. Am Soc Brew Chem J $37,47-52$

Meilgaard M, Civille GV, Carr BT (1991) Sensory Evaluation Techniques. CRC Press, Boca Raton, FL

Muir DD, Hunter EA (1991-1992) Sensory evaluation of Cheddar cheese: order of tasting and carryover effects, Food Qual Pref 3, 141-145

Naes T (1990) Handling individual differences between assessors in sensory profiling. Food Qual Pref 2, 187-199

Naes T, Solheim R (1991) Detection and interpretation of variation within and between assessors in sensory profiling. J Sens Stud 6, 159-177
Naes T, Hirst D, Baardseth P (1994) Using cumulative ranks to detect individual differences in sensory profiling. I Sens Stud 9, 87-99

Noble AC, Arnold RA, Masuda BM, Pecore SD, Schmidt JO, Stern PM (1984) Progress towards a standardized system of wine aroma terminology. Am J Enol Vitic 35, 107-109

Pagliarini E, Lembo P, Bertuccioli M (1991) Recent advancements in sensory analysis of cheese. Ital $\mathrm{J}$ Food Sci 3, 85-99

Parolari G, Virgili R, Panari G, Zannoni M (1994) Development of a vocabulary of terms for sensory evaluation of Parmigiano-Reggiano cheese by free-choice profiling. Ital J Food Sci 6, 317-324

Piggott JR (1995) Designs questions in sensory and consumer science. Food Qual Pref 6, 217-220

Piggott JR, Mowat RG (1991) Sensory aspects of maturation of Cheddar cheese by descriptive analysis. J Sens Stud 6, 49-62

Pritchett-Mangan PA (1992) Performance assessment of sensory panelists. J Sens Stud 7, 229-252

Sauvageot F (1986) L'évaluation sensorielle : une technique irremplaçable dans l'agro-alimentaire. Culture Techn 16, 306-318

Sauvageot F (1990) La construction d'un profil sensoriel. Heurts et malheurs. In : Biométrie et qualité (Asselain B, Masson JP, eds) Soc Fr Biométrie, ENSA, Rennes

Schlich P (1994) Grapes: a method and a SAS ${ }^{\circledR}$ program for graphical representations of assessors performances, J Sens Stud 9, 157-169

Schlich P (1996) Defining and validating assessor compromises about product distances and attribute correlations. In: Multivariate Analysis of Data in Sensory Science (Naes T, Risvik E, eds) Elsevier Sci Publ, Amsterdam

Stone H, Sidel JL (1985) Sensory Evaluation Practices. Academic Press, London

Vangtal A, Hammond EG (1986) Correlation of the flavor characteristics of Swiss-type cheeses with chemical parameters. J Dairy Sci 69, 2892-2993

Wakeling IN, Raats MM, MacFie HJH (1992) A new significance test for consensus in generalized Procrustes analysis. J Sens Stud 7, 91-96

Williams AA, Langron SP (1984) The use of freechoice profiling for the evaluation of commercial ports. I Sci Food Agric 35, 558-568 